\title{
Graft Polymerization of Styrene and Acrylates on the Prepolymer Having TEMPOL Residues
}

\author{
Yu Mivra, ${ }^{1}$ Yutaka Isobe, ${ }^{1}$ Tetsuya NAKAmura, ${ }^{2,3}$ \\ Motoyuki SugIURA, ${ }^{3}$ and Yoshio OKAMOTO ${ }^{1, \dagger, \dagger \dagger}$ \\ ${ }^{1}$ Department of Applied Chemistry, Graduate School of Engineering, Nagoya University, \\ Furo-cho, Chikusa-ku, Nagoya 464-8603, Japan \\ ${ }^{2}$ Joint Research Center for Precision Polymerization-Japan Chemical Innovation Institute, \\ Furo-cho, Chikusa-ku, Nagoya 464-8603, Japan \\ ${ }^{3}$ NOF Corporation, 82, Nishumon, Taketoyo-cho, Aichi 470-2398, Japan
}

(Received April 19, 2005; Accepted May 18, 2005; Published August 15, 2005)

\begin{abstract}
A simple two-step synthetic method of a graft polymer using a radical process is reported. Using living radical polymerization, graft polymers consisting of a poly(methyl methacrylate) main chain and side chains composed of various monomers, such as styrene and $n$-butyl acrylate, were synthesized. The polymers had a narrow polydispersity. Especially, for the graft polymerization of acrylates, the addition of a small amount of TEMPOL to the polymerization system on the side chain improved the livingness of the polymerization. The effect of added free TEMPOL was also studied on the homopolymerization of $n$-butyl acrylate using an initiator bearing a TEMPOL residue. [DOI 10.1295/polymj.37.617]

KEY WORDS Graft Polymer / Radical Polymerization / Acrylate / TEMPOL / NitroxideMediated Polymerization (NMP) /
\end{abstract}

The addition of a graft polymer having different monomer sequences as the main and side chains to a mixture of their homopolymers facilitates the formation of a homogenous blend. The polymer alloy thus obtained is expected to have excellent physical properties, which are valuable when used as products. The control of the side chain length of a graft polymer can produce a graft copolymer with a well-defined structure, which is expected to improve the physical properties of the surface and interface of a material. ${ }^{1-3}$ The living radical polymerization with a broad applicability $^{4-8}$ seems to be suitable to produce the graft copolymers of various monomers.

Living radical polymerizations have been achieved by several procedures including nitroxide-mediated polymerization (NMP), ${ }^{4-6}$ metal-catalyzed polymerization, ${ }^{7-9}$ reversible addition-fragmentation chain transfer (RAFT) polymerization, ${ }^{10-12}$ and organotellurium-mediated living radical polymerization (TERP). ${ }^{13}$ In the present study, we used the NMP process because of its simple procedure that can be performed without the preparation of a specific agent and the very careful precautions required for the procedure.

The nitroxides used in the NMP method are commercially available, stable in air, and easy to apply to a large-scale production. Therefore, several examples of the graft polymerization using the NMP method have been reported. ${ }^{14-17}$ Here, we used $\mathbf{1}^{18}$ bearing a 4-hydroxy-(2,2,6,6-tetramethylpiperydine1-oxyl) (TEMPOL) residue as the monomer to obtain the prepolymer with methyl methacrylate (MMA) and subsequently employed the prepolymer for the nitroxide mediated graft polymerization of styrene $(\mathrm{St})$ and $n$-butyl acrylate ( $n$-BuA) (Scheme 1$)$.

\section{EXPERIMENTAL}

\section{Materials}

MMA (Tokyo Kasei, purity $>99 \%$ ) was washed with aq. $\mathrm{NaOH}(5 \%)$ and water, dried over magnesium sulfate, and distilled over calcium hydride under reduced pressure before use. St and $n$-BuA (both Tokyo Kasei, purity >99\%) were distilled under reduced pressure before use. Cyclohexanone, $\mathrm{N}, \mathrm{N}$ dimethylformamide (DMF), and tetrahydrofuran (THF) (both Wako, purity $>99 \%$ ) were distilled under a reduced pressure before use. An initiator, tert-butylperoxypivalate, were used as received from the NOF Corporation. 4-Hydroxy-(2,2,6,6-tetramethylpiperydine-1-oxyl) (TEMPOL) (Aldrich) was also used as received.

\section{Synthesis of the Monomer Bearing a TEMPOL Residue $m$-/p-[2-Hydroxy-1-(4'-hydroxy-2', 2', 6', 6'-tetrameth-}

\footnotetext{
${ }^{\dagger}$ To whom correspondence should be addressed (E-mail: okamoto@apchem.nagoya-u.ac.jp).

${ }^{\dagger}$ Present Address: EcoTopia Science Institute, Nagoya University, Furo-cho, Chikusa-ku, Nagoya 464-8603
} 


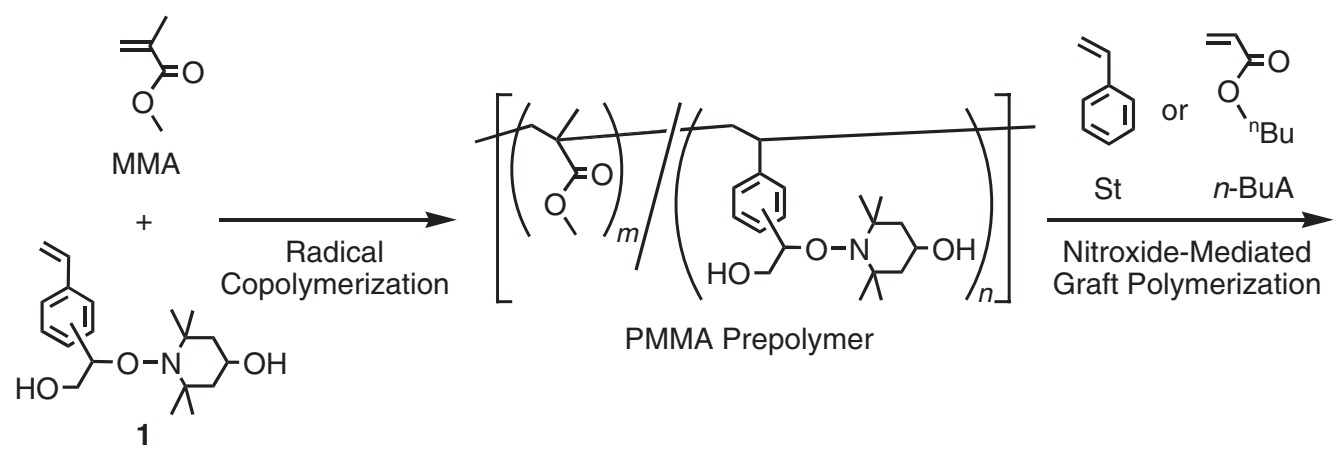

Scheme 1. Overview of graft polymerization using nitroxide-mediated polymerization.

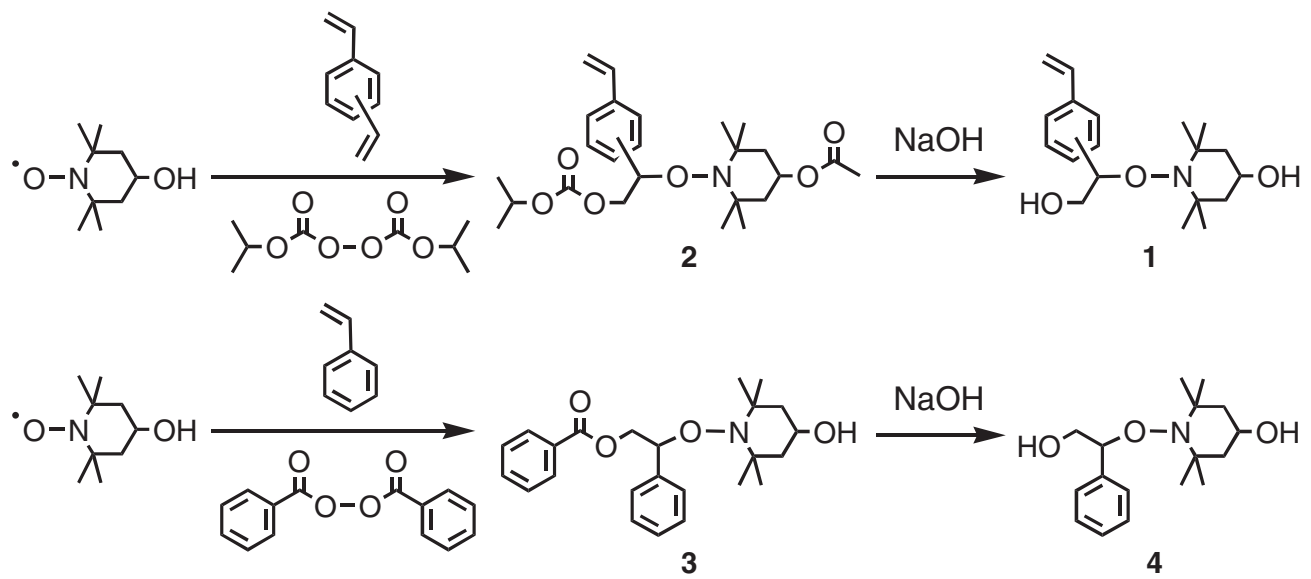

Scheme 2. Syntheses of 1-4.

ylpiperidine-1'-oxy)ethyl]styrene (1) (Scheme 2) was synthesized as follows. ${ }^{18}$ 4-Acetoxy-2,2,6,6-tetramethylpiperidine-1-oxyl $(2.14 \mathrm{~g}, 10.0 \mathrm{mmol})$ was dissolved in a mixture of 1,3- and 1,4-divinylbenzene (DVB-960, Nippon Steel Chemical Group, 15.0 g) and cooled to $0{ }^{\circ} \mathrm{C}$. To the solution was added diisopropylperoxydicarbonate $(2.08 \mathrm{~g}, 10.0 \mathrm{mmol})$ under dry nitrogen, and the mixture was heated to $55^{\circ} \mathrm{C}$ for $5 \mathrm{~h}$. After cooling, the reaction mixture was evaporated to dryness. The crude product was purified by column chromatography eluting with dichloromethane $/$ hexane $=1 / 1$ to give the purified $m-/ p$-[2isopropyloxycarbonyloxy-1-(4'-acetoxy-2', 2',6',6'-tetramethylpiperidine-1'-oxy)ethyl]styrene (2) (3.16 g, $70.5 \%)$. To a solution of $2(2.24 \mathrm{~g}, 5.0 \mathrm{mmol})$ in ethanol $(50 \mathrm{~mL})$ was added aq. $10 \% \mathrm{NaOH}$ solution $(8.0 \mathrm{~g})$ and refluxed for $2 \mathrm{~h}$. The reaction mixture was concentrated under reduced pressure and diluted with diethyl ether $(140 \mathrm{~mL})$. The solution was washed with water $(50 \mathrm{~mL} \times 3)$. The organic layer was dried with sodium sulfate and evaporated to dryness. The crude product was purified by recrystallization from a mixed solvent of ethyl acetate/hexane to afford $\mathbf{1}$ as a white solid $(1.13 \mathrm{~g}, 71.0 \%)$. ${ }^{1} \mathrm{H}$ NMR spectrum was shown in Figure 1. MS (FAB) $m / z(\%): 320[\mathrm{M}+\mathrm{H}]^{+}$; EA calcd (\%) for $\mathrm{C}_{19} \mathrm{H}_{29} \mathrm{NO}_{3}(319.21) \mathrm{C}, 71.44 ; \mathrm{H}$, 9.15; N, 4.38. Found: C, 71.40; H, 9.19; N, 4.45.

\section{Synthesis of Prepolymer}

The preparation of the prepolymer was carried out under dry nitrogen in a glass tube equipped with a 3way stopcock. In a typical polymerization, MMA (2.1 $\mathrm{mL}, 20 \mathrm{mmol}), \mathbf{1}(0.20 \mathrm{~g}, 0.65 \mathrm{mmol})$, THF $(10 \mathrm{~mL})$, and tert-butylperoxypivalate $(1.4 \mathrm{mmol}$ in $0.36 \mathrm{~mL})$ were placed in the glass tube under dry nitrogen, which was left in a thermostated bath at $60^{\circ} \mathrm{C}$ for $5 \mathrm{~h}$. The reaction was terminated by cooling them at $-78^{\circ} \mathrm{C}$. The reaction mixture was precipitated in a large excess of methanol and isolated by centrifugation. The molar ratio of MMA to $\mathbf{1}$ in the obtained polymer was determined by ${ }^{1} \mathrm{H}$ NMR. Each prepolymer was yielded around $48 \%$ after centrifugation.

\section{Graft Polymerization on the Prepolymer}

Graft polymerization was carried out in sealed glass vials. In a typical example, the prepolymer $(0.3 \mathrm{~g}$, $M_{\mathrm{n}}=40,800$ and $\left.M_{\mathrm{w}} / M_{\mathrm{n}}=1.53\right)$, styrene $(1.7 \mathrm{~mL})$, and DMF $(1.9 \mathrm{~mL})$ were mixed in a glass flask. The feed weight ratio of the prepolymer and each monomer (St, $n$-BuA) was $1 / 5$. The solution was then div- 


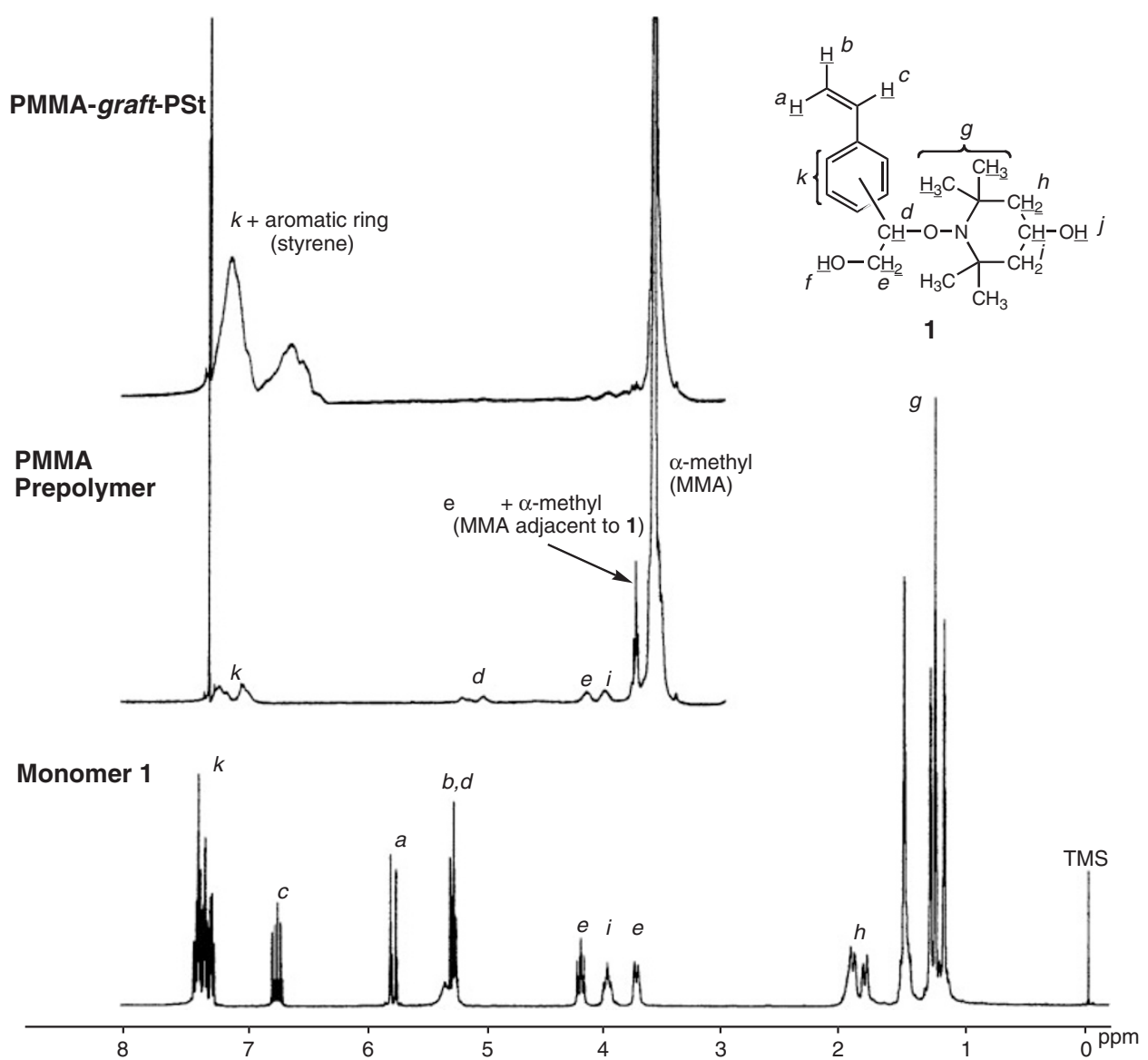

Figure 1. ${ }^{1} \mathrm{H}$ NMR analysis of intermediary products generated during the synthesis of PMMA-graft-PSt.

ided into glass vials. The vials were cooled with liquid nitrogen, evacuated, and purged with dry nitrogen. The polymerization was initiated by immersing them in a thermostated bath at $125^{\circ} \mathrm{C}$. The reaction was terminated by cooling them at $-78^{\circ} \mathrm{C}$. Homopolymerization of $n$-BuA was carried out in the same method.

\section{Separation of the Styrene Homopolymer from the} Graft Polymer

The graft polymer sample (conversion $=79.4 \%$, $\left.M_{\mathrm{n}}=113,800, M_{\mathrm{w}} / M_{\mathrm{n}}=2.06\right)$ was ground with a pestle in a mortar. The sample $(100 \mathrm{mg})$ was then added to cyclohexane $(10 \mathrm{~mL})$, which dissolves only the styrene homopolymer, and stirred for $1 \mathrm{~h}$. The mixture was divided into cyclohexane-insoluble and -soluble parts by filtration, and each part was dried under reduced pressure. The insoluble part $(50 \mathrm{mg})$ was added to cyclohexane $(5 \mathrm{~mL})$ and stirred for $1 \mathrm{~h}$. The mixture was again separated as insoluble and soluble parts by filtration.

\section{Synthesis of the Initiator Bearing TEMPOL}

The initiator (4) bearing TEMPOL was synthesized according to the synthetic method for a similar compound. ${ }^{19}$ The preparation of 1-benzyloxy-2-phenyl2-(4'-hydroxy-2', 2', 6', 6' -tetramethylpiperidine-1'-oxy)- ethane (3), a precursor of $\mathbf{4}$, was first carried out. To a solution of benzoyl peroxide $(3.00 \mathrm{~g}, 12.4 \mathrm{mmol})$ in distilled styrene $(128 \mathrm{~mL}, 1.11 \mathrm{~mol})$ was added TEMPOL $(4.80 \mathrm{~g}, 27.9 \mathrm{mmol})$ under dry nitrogen, which was heated at $80^{\circ} \mathrm{C}$ for $25 \mathrm{~h}$. After cooling, the reaction mixture was evaporated to dryness and the resulting yellow viscous liquid was purified by column chromatography eluting with chloroform/ hexane $=8 / 2$ followed by chloroform to give the purified initiator as a pale yellow solid $(0.626 \mathrm{~g}, 6.4 \%)$. To a solution of $\mathbf{3}(0.382 \mathrm{~g}, 0.962 \mathrm{mmol})$ in ethanol $(12.0 \mathrm{~mL})$ was added aq. $1 \mathrm{~N} \mathrm{NaOH}(1.20 \mathrm{~mL}, 1.20$ mmol) under dry nitrogen, which was refluxed for $2 \mathrm{~h}$. After cooling, the reaction mixture was evaporated to dryness and dissolved in a mixture of water $(20 \mathrm{~mL})$ and chloroform $(20 \mathrm{~mL})$. The aqueous layer was further extracted with chloroform $(10 \mathrm{~mL} \times 2)$, and the combined organic layers were evaporated to dryness. The crude product was purified by column chromatography eluting with chloroform followed by chloroform $/ 2$-propanol $=1 / 1$ to give the purified initiator (4) as a white solid $(0.230 \mathrm{~g}, 81.5 \%)$.

\section{Measurements}

The number average molecular weights $\left(M_{\mathrm{n}}\right)$ and polydispersities $\left(M_{\mathrm{w}} / M_{\mathrm{n}}\right)$ of the polymers were meas- 
ured by size exclusion chromatography (SEC) using THF at a flow rate $1.0 \mathrm{~mL} / \mathrm{min}$. at $40^{\circ} \mathrm{C}$ on two polystyrene gel columns; TSKgel G3000 $\mathrm{H}_{\mathrm{HR}}$ and TSKgel $\mathrm{GMH}_{\mathrm{HR}}-\mathrm{H}$, that were connected to a JASCO PU-980 precision pump and a JASCO RI-930 detector. The molecular weight was calibrated against eight standard polystyrene samples $\left(M_{\mathrm{n}}=526-900,000\right)$. The monomer conversions were determined from the concentration of the residual monomer measured by gas chromatography using methyl benzoate as the internal standard, which was added after the reaction was terminated.

\section{RESULTS AND DISCUSSION}

\section{Synthesis of the Prepolymer}

First, the copolymerization of MMA with 1 (Scheme 2) at a molar ratio of 30/1 was carried out to obtain the linear prepolymer with TEMPOL residues as the side chains. The obtained copolymer contained less MMA (22/1) compared with the feed molar ratio $(30 / 1)$. This indicates that $\mathbf{1}$ is more reactive than MMA. This result agrees with that of the copolymerization of a large excess MMA and styrene (St) under the same condition. Figure 1 shows the ${ }^{1} \mathrm{H}$ NMR spectra of the prepolymer and $\mathbf{1}$. After the copolymerization, the peaks due to a vinyl group (ac) disappeared and the peaks of the TEMPOL residues $(i, j)$ were observed in the prepolymer.

\section{Graft Polymerization of Styrene on the Prepolymer}

To the prepolymer $\left(M_{\mathrm{n}}=40,800\right.$ and $M_{\mathrm{w}} / M_{\mathrm{n}}=$ 1.53 , MMA $/ 1=22 / 1$, yield $=48 \%$ ), the St monomer was added and heated at $125^{\circ} \mathrm{C}$ in DMF to prepare graft copolymers via dissociation of the TEMPOL residues in the prepolymer. Figure 2 shows the SEC curves of the graft polymers obtained at various conversions and Figure 3 shows the plots of the St conversion versus $M_{\mathrm{n}}$ or $M_{\mathrm{w}} / M_{\mathrm{n}}$ in the graft

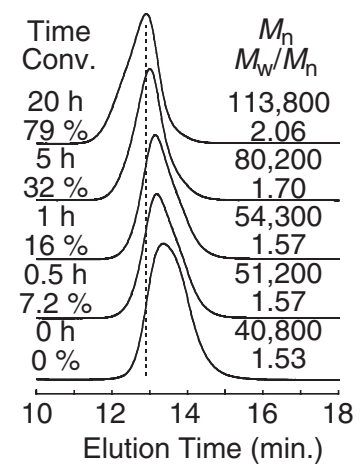

Figure 2. SEC curves of the graft polymers obtained from the prepolymer and St in DMF at $125^{\circ} \mathrm{C}$ : Prepolymer/St/DMF $=$ 0.3/1.5/1.8 (g); conv. was determined by GC.

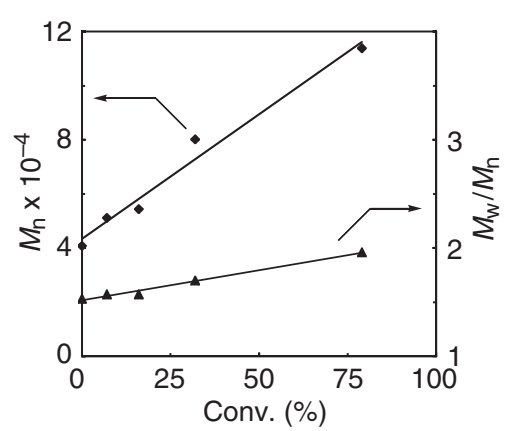

Figure 3. Conversion vs. $M_{\mathrm{n}}(\diamond)$ and $M_{\mathrm{w}} / M_{\mathrm{n}}(\boldsymbol{\Delta})$ in the graft polymerization of St.

polymerization of St on the prepolymer at the weight ratio of prepolymer $/ \mathrm{St}=1 / 5$. As the conversion increased, $M_{\mathrm{n}}$ increased without a significant increase in the polydispersity. These results support the fact that the graft polymerization proceeded in a living manner.

The graft polymerization system may also produce a styrene homopolymer. This was confirmed according to the method described in the experimental section and the results are shown in Scheme 3. From the first filtration, a cyclohexane-insoluble part (93.7 $\mathrm{mg})$ and soluble part $(4.1 \mathrm{mg})$ were obtained. The second filtration afforded a cyclohexane-insoluble part $(47.2 \mathrm{mg})$ and -soluble part $(0.1 \mathrm{mg})$. The molar ratios, 1/MMA and St/MMA, of each part calculated by ${ }^{1} \mathrm{H}$ NMR are summarized in Table I. The calculation was performed according to the following equations.

$$
\begin{aligned}
\frac{1}{\mathrm{MMA}} & =\frac{\mathrm{n}}{\mathrm{m}}=\frac{4 \mathrm{n} / 4}{3 \mathrm{~m} / 3} \\
& =\frac{\operatorname{area}(\text { aromatic ring }) / 4}{\operatorname{area}(\alpha \text {-methyl }) / 3}(=\mathrm{Y}) \\
\frac{\mathrm{St}}{\mathrm{MMA}} & =\frac{\mathrm{n}(\mathrm{p}+\mathrm{q})}{\mathrm{m}}=\frac{\{4 \mathrm{n}+5 \mathrm{n}(\mathrm{p}+\mathrm{q})-4 \mathrm{n}\} / 5}{3 \mathrm{~m} / 3} \\
& =\frac{\operatorname{area}(\text { aromatic ring }) / 5}{\operatorname{area}(\alpha \text {-methyl }) / 3}-\frac{4}{5} \mathrm{Y}
\end{aligned}
$$

The ${ }^{1} \mathrm{H}$ NMR of the cyclohexane-soluble part separated during the second filtration (Fraction $\mathrm{F}$ in Table I) indicated the absence of a polymer, suggesting that the St homopolymer was completely separated by the first filtration. Therefore, the efficiency of the graft polymerization was calculated to be $94 \%$ by the following equation.

$$
\begin{aligned}
X & =\frac{\frac{\text { St (graft polymer) }}{\text { MMA }}}{\frac{\text { St (graft polymer) }+ \text { St (homopolymer) }}{\text { MMA }}} \\
& =\frac{5.18}{5.51}=94.0(\%)
\end{aligned}
$$




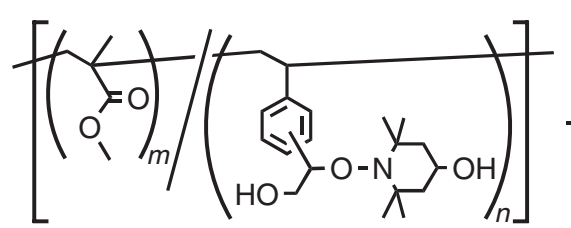

PMMA Prepolymer (A)

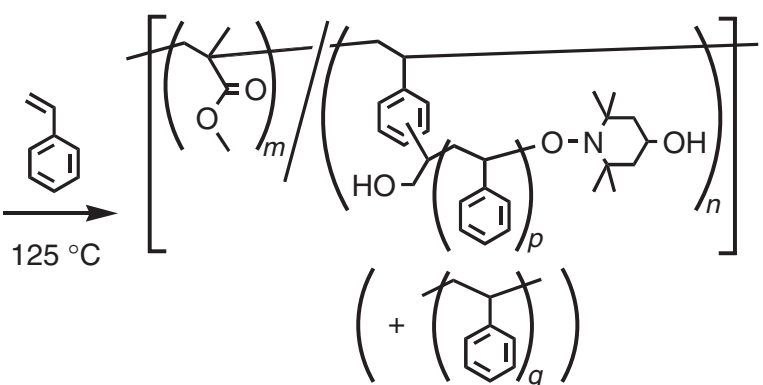

Graft Polymer + Homopolymer (B)
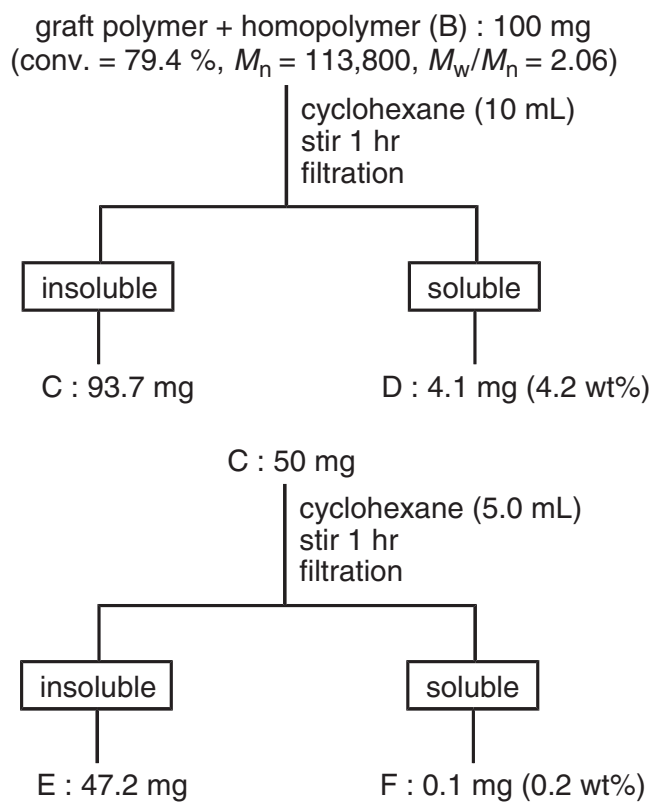

Scheme 3. Separation of the styrene homopolymer from the graft polymer.

Table I. Molar Ratios in Fractions A-F Obtained by ${ }^{1} \mathrm{H}$ NMR

\begin{tabular}{ccc}
\hline Fraction & $\begin{array}{c}\text { 1/MMA } \\
\text { molar ratio }\end{array}$ & $\begin{array}{c}\text { St/MMA } \\
\text { molar ratio }\end{array}$ \\
\hline A & 0.0461 & - \\
B & 0.0461 & 5.51 \\
C & 0.0461 & 5.28 \\
D & $\sim 0$ & $\gg 1$ \\
E & 0.0461 & 5.18 \\
F & - & - \\
\hline
\end{tabular}

The graft polymerization of styrene on the prepolymer efficiently proceeded almost without forming styrene homopolymers.

Graft Polymerization of n-Butyl Acrylate on the Prepolymer

As described above, the graft polymerization of styrene on the prepolymer proceeded in a living fashion and the graft polymers with a controlled side chain were obtained. Although the living polymerization of styrene effectively proceeded using the nitroxide, the living radical polymerization of an acrylate such as $n$-butyl acrylate ( $n$-BuA) may be difficult because this has been realized only using the designed nitroxide. $^{20-24}$ The living radical polymerization of acrylates using other initiator or catalyst systems has been reported. ${ }^{10,13,25-29}$

The graft polymerization of $n$-BuA on the prepolymer $\left(M_{\mathrm{n}}=32,400\right.$ and $M_{\mathrm{w}} / M_{\mathrm{n}}=1.46$, MMA $/ \mathbf{1}=$ $23 / 1$, yield $=43 \%$ ) was carried out in DMF at $125^{\circ} \mathrm{C}$. The polymerization did not proceed in a living manner, but reached a $94 \%$ conversion after $4 \mathrm{~h}$. The polymerization proceeded by forming both the graft polymer and the $n$-BuA homopolymer. The polymerization may start in a short time mainly by the radicals produced via the dissociation of the TEMPOL residues. However, rapid equilibrium between the TEMPOL residues and the dissociated species (Scheme 4) cannot take place due to the existence of negligible amounts of the TEMPOL radical.

To shift this equilibrium to the dormant species, small amounts of TEMPOL were added to the polymerization system. Figure 4 shows the SEC curves of the obtained polymers via the graft polymerization of $n$-BuA in the presence of TEMPOL. As the reaction 


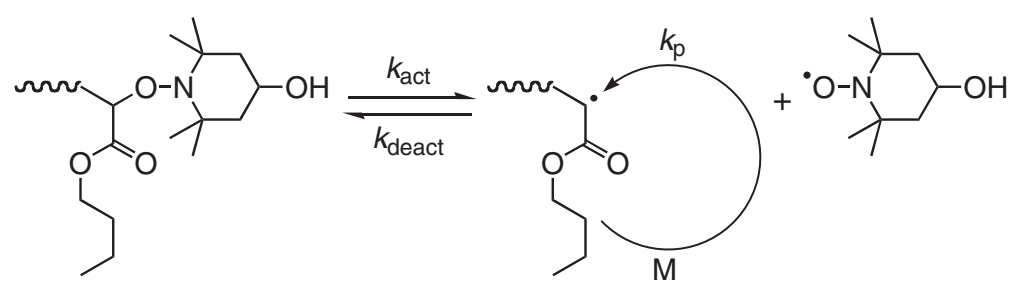

Scheme 4. Mechanism of NMP process.

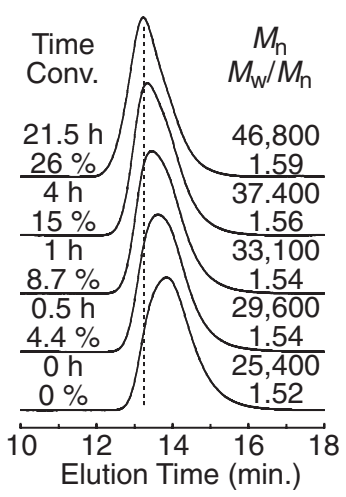

Figure 4. SEC curves of the graft polymers obtained from prepolymer and $n$-BuA in the presence of TEMPOL in $\mathrm{DMF}$ at $125^{\circ} \mathrm{C}$ : Prepolymer $/ n-\mathrm{BuA} / \mathrm{DMF}=0.3 / 1.5 / 1.8(\mathrm{~g})$; $[\text { TEMPOL }]_{0}=0.15 \mathrm{mmol} / \mathrm{L}$.

proceeded, the peak tops of the obtained polymers moved to a higher molecular weight as well as in the graft polymerization of styrene. Figure 5 shows the plots of the $n$-BuA conversion versus $M_{\mathrm{n}}$ or $M_{\mathrm{w}} /$ $M_{\mathrm{n}}$ for the graft polymerization. In the absence of TEMPOL, the polymerization rapidly proceeded and the molecular weights were almost constant regardless of the conversion. As the polymerization proceeded, the polydispersities increased and finally reached 5.0 after $4 \mathrm{~h}$. On the other hand, in the presence of TEMPOL, the graft polymerization of $n$-BuA on the prepolymer $\left(M_{\mathrm{n}}=25,400\right.$ and $M_{\mathrm{w}} / M_{\mathrm{n}}=1.52$, MMA $/ \mathbf{1}=22 / 1$, yield $=46 \%$ ) was also carried out in DMF at $125^{\circ} \mathrm{C}$. The reaction was depressed, and the molecular weights increased with an increase in the conversion, keeping the polydispersities around 1.5 .

The graft polymerization system may also produce a $n$-BuA homopolymer by undesirable thermal initiation similar to the graft polymerization of styrene. The separation of the $n$-BuA homopolymer from the graft polymer was attempted by the same method as the separation of styrene homopolymer but failed.

To confirm the effect of added free TEMPOL on the polymerization of $n$-BuA, the homopolymerization of $n$-BuA was carried out in the presence and absence of TEMPOL using the initiator 4 (Scheme 2) that has the same structure as that in the prepolymer.
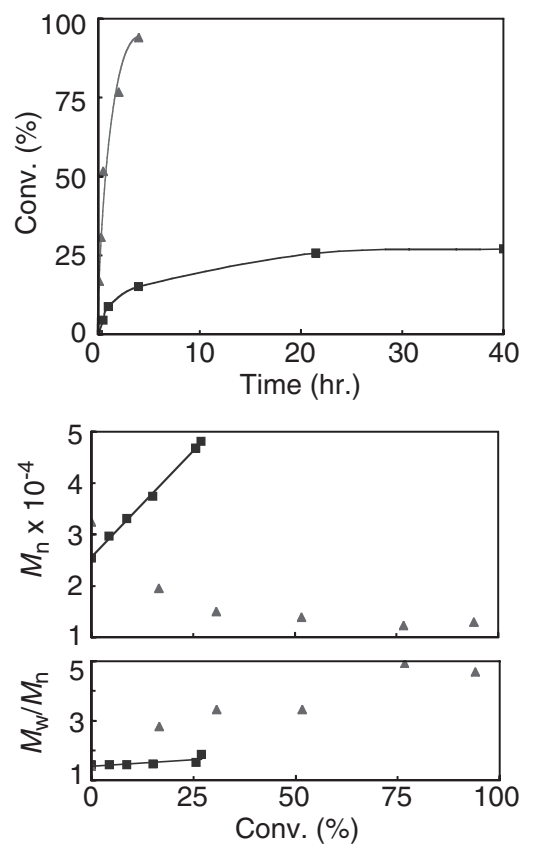

Figure 5. Time vs. conversion (top) and conversion vs. $M_{\mathrm{n}}$ and $M_{\mathrm{w}} / M_{\mathrm{n}}$ (bottom) in the graft polymerization of $n$-BuA in the absence (prepolymer: $M_{\mathrm{n}}=36,400, M_{\mathrm{w}} / M_{\mathrm{n}}=1.28$ ) (A) and presence (prepolymer: $M_{\mathrm{n}}=25,400, M_{\mathrm{w}} / M_{\mathrm{n}}=1.52$ ) (ם) of TEMPOL in DMF at $125^{\circ} \mathrm{C}$ : Prepolymer $/ n-\mathrm{BuA} / \mathrm{DMF}=0.3 /$ $1.5 / 1.8(\mathrm{~g}) ;[\text { TEMPOL }]_{0}=0.15 \mathrm{mmol} / \mathrm{L}($

The polymerization proceeded in both the cases, while a faster polymerization occurred in the absence of TEMPOL ( $42 \%$ and $25 \%$ conversion in $140 \mathrm{~h}$ ). Figure 6 shows the SEC curves of the homopolymers of $n-\mathrm{BuA}$ and the $M_{\mathrm{n}}$ and $M_{\mathrm{w}} / M_{\mathrm{n}}$ values for the main peaks of the curves. Although the main peaks of the SEC curves moved to higher molecular weight with an increase in conversion and showed narrow polydispersities in both polymerizations, narrower ones were obtained for the polymers obtained in the presence of TEMPOL. In addition, higher molecular weight fraction, which was probably formed by uncontrolled radical polymerization, was larger in the absence of TEMPOL. Furthermore, the main peaks became finally broader $\left(M_{\mathrm{w}} / M_{\mathrm{n}}=2.82\right)$, for the polymers obtained without TEMPOL in $42 \%$ conversion. These results suggest that the addition of TEMPOL reduces the concentration of the radical species and makes the polymerization more controllable. 


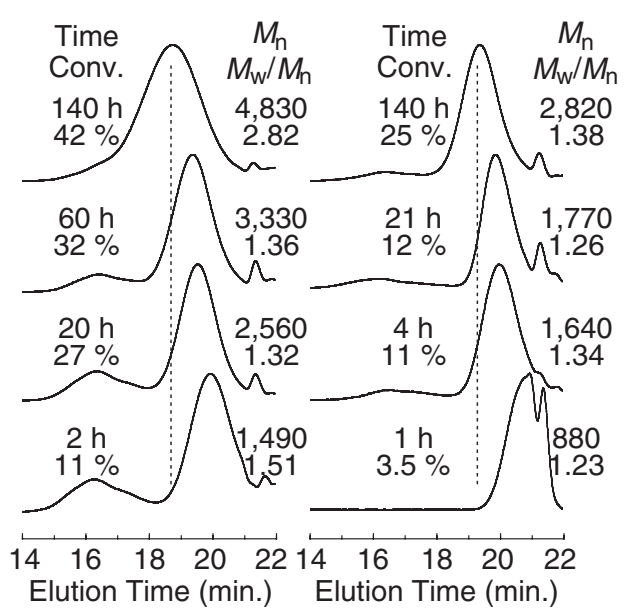

Figure 6. SEC curves of polymers of $n$ - $\mathrm{BuA}$ in the absence (left) and presence (right) of TEMPOL in DMF at $125^{\circ} \mathrm{C}: 4 / n$ $\mathrm{BuA} / \mathrm{DMF}=0.035 / 1.5 / 1.8 \quad(\mathrm{~g}) ; \quad[\mathrm{TEMPOL}]_{0}=0.15 \mathrm{mmol} / \mathrm{L}$ (right).

Table II. Graft Polymerization of $n$-BuA on the Prepolymer in Cyclohexanone at $125^{\circ} \mathrm{C}^{\mathrm{a}}$

\begin{tabular}{rccccc}
\hline Run & $\left.\begin{array}{c}\text { Molar Ratio } \\
{\left[\frac{\text { TEMPOL }]_{0}}{[1 \text { in Prepolymer }]_{0}}\right)}\end{array}\right) \begin{array}{c}\text { Time } \\
(\mathrm{h})\end{array}$ & $\begin{array}{c}\text { Conv. } \\
(\%)\end{array}$ & $\begin{array}{c}M_{\mathrm{n}}{ }^{\mathrm{c}} \\
\times 10^{-4}\end{array}$ & $\begin{array}{c}M_{\mathrm{w}}{ }^{\mathrm{c}} \\
M_{\mathrm{n}}\end{array}$ \\
\hline 1 & $5 \times 10^{-3}$ & 0 & 0 & 3.43 & 1.50 \\
2 & & 1 & 1.0 & 3.64 & 1.50 \\
3 & 3 & 5.3 & 4.23 & 1.50 \\
4 & & 5 & 13.9 & 4.73 & 1.50 \\
\hline 5 & $5 \times 10^{-4}$ & 0 & 0 & 3.43 & 1.51 \\
6 & & 1 & 14.3 & 4.96 & 1.49 \\
7 & & 3 & 18.1 & 5.61 & 1.53 \\
8 & & 5 & 23.0 & 5.94 & 1.53 \\
\hline 9 & $5 \times 10^{-5}$ & 0 & 0 & 3.43 & 1.50 \\
10 & & 1 & 19.3 & 5.66 & 1.49 \\
11 & & 3 & 22.8 & 6.21 & 1.56 \\
12 & & 5 & 24.5 & 6.78 & 1.60 \\
\hline 13 & $5 \times 10^{-6}$ & 0 & 0 & 3.39 & 1.48 \\
14 & & 1 & 20.2 & 2.29 & 1.73 \\
15 & & 3 & 24.8 & 3.08 & 1.81 \\
16 & & 5 & 26.8 & 2.11 & 3.23 \\
\hline 17 & & 0 & 0 & 3.39 & 1.48 \\
18 & 0 & 1 & 25.7 & 2.28 & 2.73 \\
19 & & 3 & 32.7 & 2.30 & 2.91 \\
20 & & 5 & 33.3 & 2.03 & 3.81 \\
\hline
\end{tabular}

${ }^{\mathrm{a} P r e p o l y m e r} / n$-BuA $/$ Cyclohexanone $=0.1 / 0.5 / 1.2(\mathrm{~g}) .{ }^{\mathrm{b}} \mathrm{De}-$ termined by GC. ${ }^{c}$ Determined by SEC in THF (PS standard).

\section{Influence of TEMPOL Concentration}

Since TEMPOL exhibited a clear effect on the polymerization, its effect on the graft polymerization of the prepolymer $\left(M_{\mathrm{n}}=34,300\right.$ and $M_{\mathrm{w}} / M_{\mathrm{n}}=1.50$, MMA $/ \mathbf{1}=22 / 1$, yield $=49 \%$ ) was further studied. The results are summarized in Table II and Figure 7. The effect on the polydispersity was clearly observed

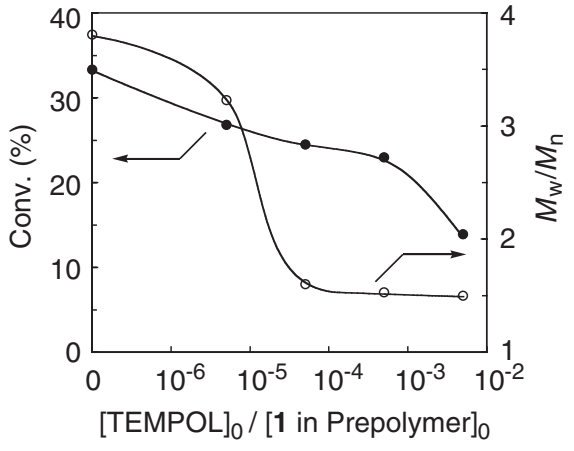

Figure 7. Effect of $[\mathrm{TEMPOL}]_{0} /[\mathbf{1} \text { in Prepolymer }]_{0}$ on conversion (๑) and $M_{\mathrm{w}} / M_{\mathrm{n}}(\bigcirc)$. The data were obtained at $5 \mathrm{~h}$ in Table II.

at $[\text { TEMPOL }]_{0} /[\mathbf{1} \text { in Prepolymer }]_{0}=5 \times 10^{-6}$ and the conversions decreased with an increase in the TEMPOL content.

\section{CONCLUSIONS}

The syntheses of the graft polymers with various side chains were carried out using the monomer 1 having a TEMPOL residue. The prepolymer was first prepared by the copolymerization of MMA and $\mathbf{1}$. The graft polymers were obtained through the dissociation of the TEMPOL residue of $\mathbf{1}$. The graft polymerization of St on the prepolymer proceeded in a living manner. The addition of a small amount of TEMPOL made the graft polymerization of $n$-BuA on the prepolymer more controllable.

Acknowledgment. This work was partly supported by the New Energy and Industrial Technology Development Organization (NEDO) under the Ministry of Economy, Trade, and Industry, Japan, through a grant for the "Nanostructure Polymer Project" in the project "Nanotechnology Materials Program" (2001-2002).

\section{REFERENCES}

1. H. R. Thomas and J. J. O'Malley, Macromolecules, 12, 323 (1979).

2. Y. Yamashita, Y. Tsukahara, K. Ito, K. Okada, and Y. Tajima, Polym. Bull., 5, 335 (1981).

3. N. M. Petel, D. W. Dwight, J. L. Hedrick, D. C. Webster, and J. E. McGrath, Macromolecules, 21, 2689 (1988).

4. M. K. Georges, R. P. N. Veregin, P. M. Kazmaier, and G. K. Hamer, Macromolecules, 26, 2987 (1993).

5. C. J. Hawker, J. Am. Chem. Soc., 116, 11185 (1994).

6. C. J. Hawker, A. W. Bosman, and E. Harth, Chem. Rev., 101, 3661 (2001) and references cited therein.

7. M. Kato, M. Kamigaito, M. Sawamoto, and T. Higashimura, Macromolecules, 28, 1721 (1995).

8. J.-S. Wang and K. Matyjaszewski, J. Am. Chem. Soc., 117, 5614 (1995). 
9. M. Kamigaito, T. Ando, and M. Sawamoto, Chem. Rev., 101, 3689 (2001) and references cited therein.

10. J. Chiefari, Y. K. (B.) Chong, F. Ercole, J. Krstina, J. Jeffery, T. P. T. Le, R. T. A. Mayadunne, G. F. Meijs, C. L. Moad, G. Moad, E. Rizzardo, and S. H. Thang, Macromolecules, 31, 5559 (1998).

11. J. F. Quinn, E. Rizzardo, and T. P. Davis, Chem. Commun., 11, 1044 (2001).

12. B. Kirci, J.-F. Lutz, and K. Matyjaszewski, Macromolecules, 35, 2448 (2002).

13. S. Yamago, K. Iida, and J.-I. Yoshida, J. Am. Chem. Soc., 124, 2874 (2002).

14. a) R. B. Grubbs, C. J. Hawker, J. Dao, and J. M. Frechet, Angew. Chem. Int. Ed. Engl., 36, 270 (1997).

b) C. J. Hawker, Acc. Chem. Res., 30, 373 (1997).

15. K. E. Russell, Prog. Polym. Sci., 27, 1007 (2002) and references cited therein.

16. N. B. Bowden, M. Dankova, W. Wiyatno, C. J. Hawker, and R. M. Waymouth, Macromolecules, 35, 9246 (2002).

17. M. Ejaz, K. Ohno, Y. Tsujii, and T. Fukuda, Polymer Prepr., Am. Chem. Soc., Div. Polym. Chem., 44, 532 (2003).

18. M. Hayashi and T. Nakamura, Jpn. Kokai Tokkyo Koho (Patent), 2000-95744 (2000).
19. C. J. Hawker, G. G. Barcley, A. Orellana, J. Dao, and W. Devonport, Macromolecules, 29, 5245 (1996).

20. N. A. Listigovers, M. K. Georges, P. G. Odell, and B. Keoshkerian, Macromolecules, 29, 8992 (1996).

21. B. Keoshkerian, A. R. Szkurhan, and M. K. Georges, Macromolecules, 34, 6531 (2001).

22. D. Benoit, V. Chaplinski, R. Braslau, and C. J. Hawker, J. Am. Chem. Soc., 121, 3904 (1999).

23. C. Farcet, B. Charleux, and R. Pirri, Macromolecules, 34, 3823 (2001).

24. N. R. Cameron and A. J. Reid, Macromolecules, 35, 9890 (2002).

25. J.-S. Wang and K. Matyjaszewski, Macromolecules, 28, 7901 (1995).

26. V. Percec, B. Barboiu, and H.-J. Kim, J. Am. Chem. Soc., 120, 305 (1998).

27. G. Moineau, M. Minet, Ph. Dubois, Ph. Teyssie, T. Senninger, and R. Jerome, Macromolecules, 32, 27 (1999).

28. H. Uegaki, Y. Kotani, M. Kamigaito, and M. Sawamoto, Macromolecules, 31, 6756 (1998).

29. I. Ohishi, K.-Y. Baek, Y. Kotani, M. Kamigaito, and M. Sawamoto, J. Polym. Sci., Part A: Polym. Chem., 40, 2033 (2002). 